\title{
Lower Arterial Cross-Sectional Area of Carotid and Vertebral Arteries and Higher Frequency of Secondary Neck Vessels Are Associated with Multiple Sclerosis
}

\author{
(D) P. Belov, (DD. Jakimovski, (D). Krawiecki, (D) C. Magnano, (D). Hagemeier, (D). Pelizzari, (D) B. Weinstock-Guttman, and (D). Zivadinov

\begin{abstract}
BACKGROUND AND PURPOSE: Arterial and neck vessel system characteristics of patients with multiple sclerosis have not been previously investigated. Therefore, the aim of this study was to examine the frequency of neck vessels and their cross-sectional areas (in square millimeters) between patients with MS and healthy controls.
\end{abstract}

MATERIALS AND METHODS: In this study, 193 patients with MS and 193 age- and sex-matched healthy controls underwent 2D TOF venography at 3T. The main arterial (carotid and vertebral), venous (internal jugular), and secondary neck vessels were examined at 4 separate cervical levels (C2/3, C4, C5/6, and C7/T1). The ANCOVA adjusted for age, body mass index, smoking status, hypertension, and heart disease was used to compare the differences between patients with MS and healthy controls.

RESULTS: After controlling for all confounding factors, patients with MS had significantly lower cross-sectional areas of the carotid arteries at the $C 2 / 3(P=.03), C 5 / 6(P=.026)$, and C7/T1 $(P=.005)$ levels as well as of the vertebral arteries at the C2/3 $(P=.02), C 4(P=$ $.012)$, and $\mathrm{C} 7 / \mathrm{Tr}(P=.006)$ levels, compared with healthy controls. A higher frequency of secondary neck vessels was found at all 4 levels in patients with MS: C2/3 (12.9 versus 10, $P<.001$ ), C4 (9.1 versus 7.5, $P<.001), C 5 / 6$ (7.8 versus 6.8, $P=.012$ ), and C7/T1 ( 8.8 versus $6, P<.001$ ). The total cross-sectional areas of secondary neck vessels were also significantly higher at all 4 levels $(P<.03)$. No significant differences in the cross-sectional areas of jugular veins were found between patients with MS and healthy controls.

CONCLUSIONS: Patients with MS showed lower cross-sectional areas of the carotid and vertebral arteries and a higher frequency of secondary neck vessels and their cross-sectional areas compared with healthy controls.

ABBREVIATIONS: $\mathrm{BMI}=$ body mass index; $\mathrm{CCA}=$ common carotid artery; $\mathrm{CSA}=$ cross-sectional area; $\mathrm{ECA}=$ external carotid artery; $\mathrm{HC}=$ healthy controls; IJV $=$ internal jugular vein; $\mathrm{VA}=$ vertebral artery

M ultiple sclerosis is the most common neurologic disease responsible for disability in the active working population. Overlapping mechanisms of chronic autoimmune demyelination and progressive neurodegeneration are hallmarks of the disease pathophysiology, which is highly variable through the spectrum of the MS course. ${ }^{1}$ Due to the vast heterogeneity of the disease

Received May 23, 2017; accepted after revision August 17.

From the Buffalo Neuroimaging Analysis Center, Department of Neurology (P.B., D.J., J.K., C.M., J.H., R.Z.), Jacobs MS Center, Department of Neurology (B.W.-G.), and Center for Biomedical Imaging at Clinical Translational Science Institute (R.Z.), University at Buffalo, State University of New York, Buffalo, New York; Department of Electronics, Information and Bioengineering (L.P.), Politecnico di Milano, Milan, Italy; and Fondazione Don Carlo Gnocchi Organizzazione Non Lucrativa di Utilita' Sociae (L.P.), Milan, Italy.

This study was funded, in part, by The Annette Funicello Research Fund for Neurological Diseases and internal resources of the Buffalo Neuroimaging Analysis Center. In addition, we received support from the Jacquemin Family Foundation. Research reported in this publication was also funded, in part, by the National Center for Advancing Translational Sciences of the National Institutes of Health under award No. ULITR001412. The content is solely the responsibility of the authors and does not necessarily represent the official views of the National Institutes of Health. presentation, research has taken different routes to understanding the potential multifactorial interplay of the autoimmune, degenerative, environmental, genetic, and cardiovascular factors. ${ }^{2}$

Evidence is mounting that increased MS prevalence and disease severity are associated with more frequent cardiovascular risk factors, such as obesity and hypertension. ${ }^{3}$ Sedentary lifestyle, lack of exercise, ${ }^{4}$ hypertension, ${ }^{5,6}$ smoking status, ${ }^{7}$ altered lipid metabolism, ${ }^{8}$ and especially obesity in the early developmental stages $^{9}$ have all been consistently associated with an earlier MS disease onset, accelerated disability progression, and worse inflammatory and neurodegenerative disease outcomes. A recent

Please address correspondence to Robert Zivadinov, MD, PhD, FAAN, FEAN, FANA, Translational Imaging Center at Clinical Translational Science Institute, Buffalo Neuroimaging Analysis Center, Jacobs School of Medicine and Biomedical Sciences, University at Buffalo, State University of New York, 100 High St, Buffalo, NY 14203; e-mail: rzivadinov@bnac.net

\footnotetext{
- Indicates open access to non-subscribers at www.ajnr.org

三 Indicates article with supplemental on-line tables.

Indicates article with supplemental on-line photo.

http://dx.doi.org/10.3174/ajnr.A5469
} 
nationwide study in Denmark that included 8947 patients with MS and 44,735 healthy controls (HC) showed a lower occurrence of cerebrovascular comorbidities before MS onset, followed by a higher occurrence after the MS disease onset. ${ }^{10}$ Therefore, there is an increasing interest in understanding pathophysiologic mechanisms by which cardiovascular factors may influence the MS disease course and severity.

Investigating the head and neck vascular circulation is the crucial common ground for better understanding of the association between cardiovascular comorbidities and MS. Because this system is a constitutional member of the blood-brain barrier, any alteration in its integrity may have a deleterious impact on both systems. Therefore, examining information about the neck vessel cross-sectional area (CSA) is crucial to further understanding the associations between the extracranial and intracranial vascular changes observed in MS. However, a comprehensive all-inclusive approach to studying the CSA of the arterial and venous systems of neck vessels is generally lacking. In addition, the extent of normal vascular variation due to age, sex, and body mass index (BMI) has not been fully investigated, to our knowledge.

Previous studies examined the importance of some vascular aspects of MS using perfusion imaging. ${ }^{11}$ Both positron-emission tomography ${ }^{12}$ and dynamic-susceptibility contrast perfusion MR imaging studies showed a widespread reduction in cerebral blood flow affecting both the white and gray matter. ${ }^{11}$ Reports of impairment in cerebrovascular coupling and reactivity ${ }^{13}$ may additionally explain the cause of the neurodegenerative processes in MS. Patients with MS also demonstrated cerebrovascular reactivity impairment in different brain networks, notably within the default mode networks. ${ }^{14}$ While the pathogenesis of these intracerebral perfusion alterations is unknown, it may be due to cardiovascular comorbidities or chronic high nitric oxide levels associated with the disease pathology. ${ }^{15}$

Against this background, we aimed to examine the frequency of the neck vessels and their CSA (in square millimeters) between patients with MS and HC. Additionally, we explored possible confounding factors such as age, vascular comorbidities, and BMI in comparing the neck vascular systems in patients with MS and HC.

\section{MATERIALS AND METHODS Study Participants}

Study participants included in this study are part of an ongoing prospective study of the cardiovascular, environmental, and genetic risk factors in MS that enrolled $>1000$ subjects with MS and HC. ${ }^{16}$ Inclusion criteria for this substudy investigating the characteristics of neck vessels in MS were the following: 1) MR venography examination performed within 30 days of the clinical examination, 2) age range of $18-80$ years, 3) MS defined by the 2010 revised McDonald criteria, ${ }^{17}$ or 4 ) being a healthy control without a known history of neurologic disorder. Exclusion criteria were the following: 1) known history of morphologic vascular abnormalities (Klippel-Trenaunay-Weber, Parkes Weber, Servelle-Martorell, or Budd-Chiari syndromes), 2) secondary-progressive or primary-progressive MS, and 3) pregnant or nursing mothers.

One hundred ninety-three patients with MS and 193 age- and sex-matched HC underwent health screening and physical, neu- rologic, and MR imaging examinations. Histories of smoking, heart disease, and hypertension were also collected using structured questionnaires in concordance with cross-examination of hospital medical records for all subjects. The subjects were divided into never/ever smokers. Active smokers were classified as individuals who smoked $>10$ cigarettes per day in the 3 months before the start of the study. Subjects were classified as past smokers if they smoked consecutively for a minimum of 6 months at some point in the past. ${ }^{7}$ Heart disease included diagnosis of congestive heart failure, heart attack, arrhythmia, valvar disorders, heart murmurs, or heart surgery. Diagnosis of hypertension was performed according to the Seventh Report of the Joint National Committee on Prevention, Detection, Evaluation, and Treatment of High Blood Pressure. ${ }^{18}$ Subjects with stage 1 (systolic blood pressure of 140-159 mm Hg or diastolic blood pressure of 90-99 $\mathrm{mm} \mathrm{Hg}$ ) and stage 2 (systolic blood pressure $\geq 160 \mathrm{~mm} \mathrm{Hg}$ or diastolic blood pressure of $\geq 100 \mathrm{~mm} \mathrm{Hg}$ ) were classified as hypertense. BMI was assessed in all subjects. Patients with MS were examined using the Expanded Disability Status Scale by an experienced neurologist.

The study was approved by the institutional review board of State University of New York at Buffalo, and all subjects signed the written informed consent form.

\section{MR Imaging Acquisition and Analysis}

All scans were acquired on a 3T Signa Excite HD 12.0 Twin Speed scanner (GE Healthcare, Milwaukee, Wisconsin) using an 8-channel head and neck coil. Both neck vessel frequency and the CSAs of the vessels were measured using a $2 \mathrm{D}-\mathrm{MRV}$ sequence that consisted of 150 slices ( $1.5 \mathrm{~mm}$ thick) using a $320 \times 192$ matrix and a $22.0-\mathrm{cm}$ FOV. The phase FOV was $75 \%$ for a resolution of $0.69 \times 1.15 \times 1.5$ $\mathrm{mm}^{3}$. Imaging parameters were TE/TR/flip angle of $4.3 \mathrm{~ms} / 14 \mathrm{~ms} /$ $70^{\circ}$ and total acquisition time of 5 minutes 19 seconds.

Neck vessels were examined at 4 separate cervical levels, including C2/C3, C4, C5/C6, and C7/T1. At first, 2 trained operators (P.B. and C.M., each with a minimum of 5 years of experience) determined the CSA of the common carotid (CCA), internal carotid, external carotid (ECA), and vertebral arteries (VA) and the internal jugular veins (IJVs). In cervical sections above the bifurcation of the CCA $(\mathrm{C} 4$ or $\mathrm{C} 2 / \mathrm{C} 3)$, the CSAs of both the ICA and the ECA were added together. The total CSA of each vessel was calculated by summing values from both the corresponding left- and right-sided measurements. Because the vertebral vein is not commonly present in all subjects, ${ }^{19}$ it was classified as an accessory drainage pathway and included in the segmentation of secondary vessels. Due to the possible presence of slow and tortuous flow that might create signal saturation within very small vessels, the secondary vessel inclusion threshold was set to 2.0 $\mathrm{mm}^{2}$. All visible neck vessels at the 4 cervical levels were marked, their frequencies were manually counted, and their CSAs were assessed. Additional vessel exclusion criteria were the following: 1) vessels that created loops in the rostrocaudal direction, and 2) the operator not being able to trace the detected signal on slices above and below the designated level.

The CSAs of all neck vessels were determined with the Java Image Manipulation Tool (JIM), Version 7.0 (http://www.xinapse.com) ROI Toolkit. For the best edge selection, the Contour ROI Tool, a 


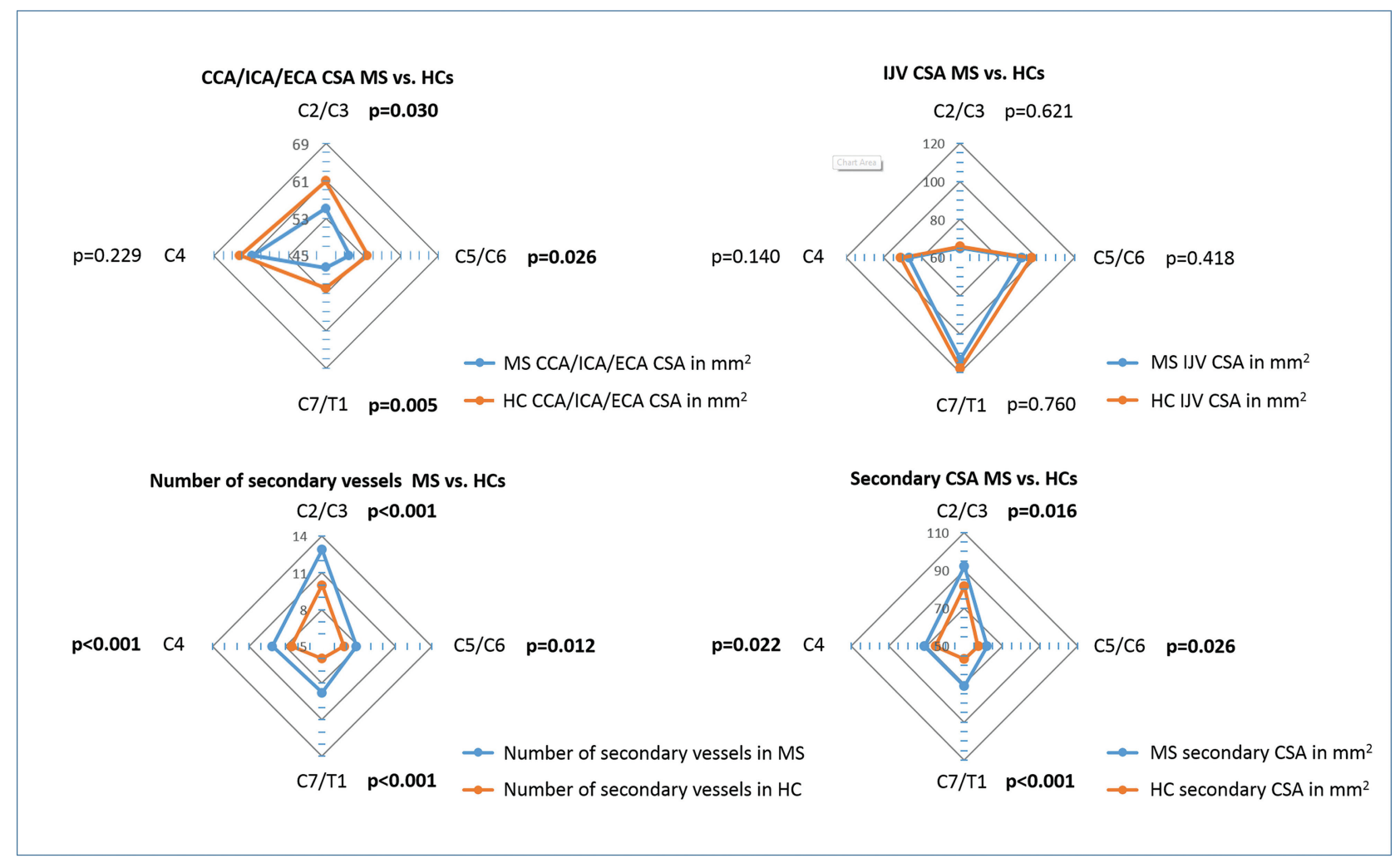

FIG 1. Radar plot representation of the neck vessel differences between patients with multiple sclerosis and healthy controls. Significant correlations are in boldface.

part of the automated Preview Contours Toolbox was used. If necessary, the operator manually adjusted the ROI boundary. The manual adjustment was mainly used in the following: 1) MRV scans with substantial image noise on the predetermined contrast, 2) to separate 2 close-but-different vessels when the automated contouring tool highlighted both, and 3) to exclude signal from arising vessel branches. The maximum contrast was preset at a 900 intensity. The general rule of determining the ideal analysis contrast was based on the stability of the signal boundaries. Meticulous segmentation of the main arterial, venous, and secondary vessels at the 4 cervical levels was performed, with high reproducibility (interclass correlation, $>0.818 ; P<.001)$ (On-line Table 1). ${ }^{20}$ The On-line Figure shows an example of corresponding vessel selection and representative CSA measurements in a healthy control.

\section{Statistical Analysis}

Statistical analyses were performed using SPSS, Version 24.0 (IBM, Armonk, New York). For clinical and demographic comparisons between the groups, $\chi^{2}$ cross-tabulation and the Student $t$ test were used accordingly. To determine associations between number of neck vessels and their cross-sectional areas with age and BMI, we used a Spearman rank correlation.

The ordinal variables regarding the secondary vessel frequency were transformed into a ranked-order type. Differences in neck vessel frequency and size (CSA) between MS and HC groups were assessed with analysis of covariance adjusted for age, BMI, smoking history, heart disease, and hypertension. Radar plots were used to visualize the data in a comprehensive manner (Fig 1). All analyses were additionally repeated in subgroups of subjects with- out the presence of cardiovascular comorbidities (obesity, heart disease, hypertension, diabetes mellitus type 1), to further control whether the findings were related to cardiovascular comorbidities. To examine the smoking effect on the CSA measures, we performed additional supplemental analysis in patients with MS who were smokers and nonsmokers.

In all analyses, a minimum significance level of $P \leq .05$ based on a 2 -tailed test was considered statistically significant.

\section{RESULTS}

\section{Demographic and Clinical Characteristics}

All 193 patients with MS had relapsing-remitting MS. Demographic and clinical information is summarized in Table 1 . The ratio of women within both groups was 130/193 (67.4\%). Patients with MS were $42.2 \pm 13.9$ years of age, with a mean BMI of $26.8 \pm$ 5.8 , a mean disease duration of $12 \pm 9.4$ years, and a median Expanded Disability Status Scale score of 2.0. The HC group was $42.9 \pm 17.5$ years of age and had an average BMI of $26.8 \pm 5.7$. There were no significant differences between both groups regarding age $(P=.676)$, sex $(P=1.000)$, and BMI $(P=.940)$. Only 2 patients with MS and 1 healthy control had a diagnosis of type 1 diabetes mellitus. However, the cardiovascular burden was higher in the MS group versus $\mathrm{HC}$, including smoking history $(P=.005)$ and hypertension $(P=.001)$, and there was a trend toward an increased prevalence of heart disease $(P=.053)$. The demographic and clinical information regarding the subgroup of subjects without hypertension and heart disease is summarized in On-line Table 2. 


\section{Age and BMI Associations with the Size and the Number of Secondary Neck Vessels}

The relationship between age and neck vessels is depicted in Table 2. Age showed a significant inverse correlation with the number of secondary neck vessels in HC. The older HC population had fewer vessels measured at the $\mathrm{C} 2 / 3(P=.039), \mathrm{C} 4(P=.003), \mathrm{C} 5 / 6(P=$ $.05)$, and $\mathrm{C} 7 / \mathrm{T} 1(P=.031)$ levels. On the contrary, no significant association of age and frequency of secondary neck vessels was found in patients with MS. Age was not associated with total secondary vessel CSA in either patients with MS or HC. As shown for the secondary vessels, the same analysis of correlations between the arterial CSA and age was performed. No association was found between age and arterial CSA at any cervical level, except at the $\mathrm{C} 2 / 3$ level in both MS and HC cohorts $(P=.031$ and $P=.023$, respectively). On the contrary, both patients with MS and HC showed a significant association of age and increased IJV CSA.

BMI showed an even stronger inverse association with the frequency of secondary neck vessels in HC and patients with MS (Table 2). HC with lower BMIs had a higher frequency of secondary vessels measured at the $\mathrm{C} 2 / 3(P=.05), \mathrm{C} 4(P<.001), \mathrm{C} 5 / 61$ $(P=.001)$, and C7/T1 $(P=.025)$ levels. Similarly, a lower BMI in

Table 1: Demographic and clinical characteristics of patients with multiple sclerosis $(n=193)$ and healthy controls $(n=193)^{a}$

\begin{tabular}{lccc} 
& MS $(\boldsymbol{n}=193)$ & HC $(\boldsymbol{n}=193)$ & $\boldsymbol{P}$ Value \\
\hline Female (No.) (\%) & $130(67.4)$ & $130(67.4)$ & 1.000 \\
Age (mean) (SD) (yr) & $42.2(13.9)$ & $42.9(17.5)$ & .676 \\
BMI (mean) (SD) & $26.8(5.8)$ & $26.8(5.7)$ & .94 \\
Disease duration (mean) (SD) (yr) & $12.0(9.4)$ & $\mathrm{NA}$ & - \\
EDSS (median) (range) & $2(0.0-6.5)$ & $\mathrm{NA}$ & - \\
Smoking history (No.) (\%) & $73(46.8)$ & $58(32.4)$ & $.005^{\mathrm{b}}$ \\
Heart disease (No.) (\%) & $30(19.7)$ & $20(12.4)$ & .053 \\
Hypertension (No.) (\%) & $38(25.3)$ & $19(11.3)$ & $.001^{\mathrm{b}}$ \\
\hline
\end{tabular}

Note:-EDSS indicates Expanded Disability Status Scale; IQR, interquartile range; NA, not applicable.

${ }^{a} \chi^{2}$ and Student $t$ test were used for comparing variables between groups.

${ }^{\mathrm{b}}$ An $\alpha$ level of .05 was considered significant. patients with MS was associated with a higher frequency of secondary neck vessels at the $\mathrm{C} 2 / 3$ level $(P=.007)$, C4 level $(P<$ $.001)$, C5/6 level $(P<.001)$, and C7/T1 level $(P=.017)$. The CSA of the secondary neck vessels showed an inverse association with BMI in patients with MS at the $\mathrm{C} 2 / 3, \mathrm{C} 4$, and $\mathrm{C} 5 / 6$ levels $(P<$ $.01)$.

\section{Differences between MS and HC Cohorts in Arterial, Venous, and Secondary Neck Vessel Frequency and Cross-Sectional Area}

The frequency and size of the arterial, venous, and secondary neck vessels in both MS and HC groups are summarized in Tables 3 and 4 and Fig 1 . Due to the age and BMI dependency exhibited by the size and number of the secondary vessels in patients with MS and $\mathrm{HC}$, as well as cardiovascular risk factor differences between the 2 groups, all comparisons were adjusted for age, BMI, smoking history, heart disease, and hypertension.

After we controlled for these confounding factors, patients with MS had a significantly lower CSA of the carotid arteries at $\mathrm{C} 2 / 3(55.1 \pm 16.4$ versus $60.9 \pm 17.9, P=.03), \mathrm{C} 5 / 6(50.1 \pm 10.1$ versus $53.9 \pm 12.5, P=.026)$, and $\mathrm{C} 7 / \mathrm{T} 1(47.6 \pm 9.8$ versus $52 \pm$ 9.9, $P=.005)$ levels, as well as of the vertebral arteries at the $\mathrm{C} 2 / 3(20.1 \pm 4.4$ versus $21.8 \pm 5.8, P=.02), \mathrm{C} 4(18.6 \pm$ 4.2 versus $20.3 \pm 5, P=.012)$, and $\mathrm{C} 7 / \mathrm{T} 1(16.3 \pm 4.5$ versus $18.4 \pm 5.9, P=$ .006) levels, compared with HC. A higher frequency of secondary neck vessels was found at all 4 levels in patients with MS: C2/3 (12.9 versus $10, P<$ $.001), \mathrm{C} 4$ (9.1 versus $7.5, P<.001), \mathrm{C} 5 / 6$ (7.8 versus $6.8, P=.012$ ), and $\mathrm{C} 7 / \mathrm{T} 1$ (8.8 versus $6, P<.001)$. The total CSA of

Table 2: Correlations of arterial, venous, and secondary neck vessel frequency and the cross-sectional area with age and BMI in study groups $^{\mathrm{a}}$

\begin{tabular}{|c|c|c|c|c|c|c|c|c|}
\hline & \multicolumn{4}{|c|}{ Age } & \multicolumn{4}{|c|}{ Body Mass Index } \\
\hline & \multicolumn{2}{|c|}{ MS $(n=193)$} & \multicolumn{2}{|c|}{ HC $(n=193)$} & \multicolumn{2}{|c|}{ MS ( $n=193)$} & \multicolumn{2}{|c|}{$\mathrm{HC}(n=193)$} \\
\hline & $R$ Value & $P$ Value & $R$ Value & $P$ Value & $R$ Value & $P$ Value & $R$ Value & $P$ Value \\
\hline \multicolumn{9}{|c|}{ Arterial CSA $\left(\mathrm{mm}^{2}\right)$} \\
\hline $\mathrm{C} 2 / 3$ & -0.156 & $.031^{\mathrm{b}}$ & -0.163 & $.023^{b}$ & 0.130 & .085 & 0.059 & .449 \\
\hline $\mathrm{C4}$ & 0.075 & .298 & 0.045 & .534 & 0.037 & .626 & -0.017 & .830 \\
\hline $\mathrm{C} 5 / 6$ & 0.103 & .156 & 0.122 & .092 & 0.136 & .073 & 0.095 & .224 \\
\hline $\mathrm{C} 7 / \mathrm{Tl}$ & -0.049 & .502 & -0.003 & .968 & 0.085 & .266 & 0.047 & .548 \\
\hline \multicolumn{9}{|c|}{ IJV CSA $\left(\mathrm{mm}^{2}\right)$} \\
\hline $\mathrm{C} 2 / 3$ & 0.257 & $<.001^{\mathrm{b}}$ & 0.150 & .37 & 0.098 & .198 & 0.083 & .287 \\
\hline $\mathrm{C} 4$ & 0.255 & $<.001^{\mathrm{b}}$ & 0.177 & $.14^{\mathrm{b}}$ & 0.146 & .054 & 0.139 & .075 \\
\hline $\mathrm{C} 5 / 6$ & 0.196 & $.006^{\mathrm{b}}$ & 0.252 & $<.001^{\mathrm{b}}$ & 0.339 & $<.001^{\mathrm{b}}$ & 0.231 & $.003^{\mathrm{b}}$ \\
\hline $\mathrm{C} 7 / \mathrm{Tl}$ & 0.187 & $.009^{\mathrm{b}}$ & 0.327 & $<.001^{\mathrm{b}}$ & 0.375 & $<.001^{\mathrm{b}}$ & 0.344 & $<.001^{\mathrm{b}}$ \\
\hline \multicolumn{9}{|c|}{ Secondary CSA $\left(\mathrm{mm}^{2}\right)$} \\
\hline $\mathrm{C} 2 / 3$ & 0.039 & .594 & -0.060 & .404 & -0.192 & $.011^{\mathrm{b}}$ & -0.074 & .347 \\
\hline $\mathrm{C4}$ & 0.112 & .122 & -0.040 & .584 & -0.229 & $.002^{b}$ & -0.121 & .121 \\
\hline $\mathrm{C} 5 / 6$ & 0.047 & .518 & 0.028 & .696 & -0.214 & $.004^{\mathrm{b}}$ & -0.064 & .417 \\
\hline $\mathrm{C} 7 / \mathrm{Tl}$ & 0.061 & .398 & -0.049 & .498 & -0.078 & .307 & -0.065 & .405 \\
\hline \multicolumn{9}{|c|}{ No. of vessels } \\
\hline $\mathrm{C} 2 / 3$ & 0.013 & .860 & -0.149 & $.039^{\mathrm{b}}$ & -0.204 & $.007^{\mathrm{b}}$ & -0.153 & $.050^{\mathrm{b}}$ \\
\hline $\mathrm{C} 4$ & -0.460 & .527 & -0.211 & $.003^{\mathrm{b}}$ & -0.292 & $<.001^{\mathrm{b}}$ & -0.316 & $<.001^{\mathrm{b}}$ \\
\hline$C 5 / 6$ & -0.076 & .294 & -0.141 & $.050^{\mathrm{b}}$ & -0.333 & $<.001^{\mathrm{b}}$ & -0.251 & $.001^{\mathrm{b}}$ \\
\hline $\mathrm{C} 7 / \mathrm{Tl}$ & -0.060 & .406 & -0.155 & $.031^{\mathrm{b}}$ & -0.180 & $.017^{\mathrm{b}}$ & -0.174 & $.025^{\mathrm{b}}$ \\
\hline
\end{tabular}

Spearman ranked correlations between age/BMl and the corresponding vascular variable were used.

${ }^{\mathrm{b}}$ An $\alpha$ level of .05 was considered significant. 
Table 3: Arterial, venous, and secondary neck vessel frequency and the cross-sectional area in the study groups ${ }^{\mathrm{a}}$

\begin{tabular}{|c|c|c|c|c|c|c|}
\hline & \multicolumn{6}{|c|}{ Primary Vessel (CSA) $\left(\mathrm{mm}^{2}\right)$} \\
\hline & \multicolumn{3}{|c|}{ Arterial and Venous } & \multicolumn{3}{|c|}{ Arterial (VAs) } \\
\hline & MS $(n=193)$ & $\mathrm{HC}(n=193)$ & $P$ Value & MS $(n=193)$ & HC $(n=193)$ & $P$ Value \\
\hline \multicolumn{7}{|c|}{ Arterial (CCA/ICA/ECA) } \\
\hline $\mathrm{C} 2 / \mathrm{C}$ & $55.1(16.4)$ & 60.9 (17.9) & $.030^{\mathrm{b}}$ & $20.1(4.4)$ & $21.8(5.8)$ & $.02^{\mathrm{b}}$ \\
\hline $\mathrm{C} 4$ & $60.8(15.7)$ & $63.4(16.3)$ & .229 & $18.6(4.2)$ & $20.3(5.0)$ & $.012^{b}$ \\
\hline $\mathrm{C} 5 / \mathrm{C} 6$ & $50.1(10.1)$ & 53.9 (12.5) & $.026^{b}$ & $18.1(6.9)$ & $19.3(4.7)$ & .341 \\
\hline $\mathrm{C} 7 / \mathrm{Tl}$ & $47.6(9.8)$ & $52(9.9)$ & $.005^{b}$ & $16.3(4.5)$ & $18.4(5.9)$ & $.006^{\mathrm{b}}$ \\
\hline \multicolumn{7}{|c|}{ Venous (IJVs) } \\
\hline $\mathrm{C} 2 / \mathrm{C}^{\circ}$ & $64.9(27.4)$ & $66.0(31.6)$ & .621 & & & \\
\hline $\mathrm{C} 4$ & $86.9(35.9)$ & $91.1(41.0)$ & .140 & & & \\
\hline $\mathrm{C} 5 / \mathrm{C} 6$ & $92.3(57.1)$ & $97.4(60.2)$ & .418 & & & \\
\hline $\mathrm{C} 7 / \mathrm{T} 7$ & $113.3(67.0)$ & 117.9 (79.3) & .790 & & & \\
\hline
\end{tabular}

${ }^{a}$ Analysis of covariance adjusted for age and BMI, smoking history, heart disease, and hypertension was used. In the ANCOVA for frequency of vessels, ranked variables were used.

${ }^{\mathrm{b}}$ An $\alpha$ level of .05 was considered significant.

Table 4: Secondary neck vessel frequency and the cross-sectional area in the study groups ${ }^{\mathrm{a}}$

\begin{tabular}{|c|c|c|c|c|c|c|}
\hline & \multicolumn{3}{|c|}{ No. of Vessels } & \multicolumn{3}{|c|}{$\mathrm{CSA}\left(\mathrm{mm}^{2}\right)$} \\
\hline & $\begin{array}{c}\text { MS } \\
(n=193)\end{array}$ & $\begin{array}{c}\text { HC } \\
(n=193)\end{array}$ & $\begin{array}{c}P \\
\text { Value }\end{array}$ & $\begin{array}{c}\text { MS } \\
(n=193)\end{array}$ & $\begin{array}{c}\text { HC } \\
(n=193)\end{array}$ & $\begin{array}{c}P \\
\text { Value }\end{array}$ \\
\hline \multicolumn{7}{|c|}{ Secondary vessels } \\
\hline $\mathrm{C} 2 / \mathrm{C}^{2}$ & $12.9(5.4)$ & $10(4.2)$ & $<.001^{\mathrm{b}}$ & $92.1(40.6)$ & $81.6(35.5)$ & $.016^{\mathrm{b}}$ \\
\hline $\mathrm{C} 4$ & $9.1(4.2)$ & $7.5(3.3)$ & $<.001^{\mathrm{b}}$ & $71.0(33.7)$ & $65.3(28.7)$ & $.022^{\mathrm{b}}$ \\
\hline $\mathrm{C} 5 / \mathrm{C} 6$ & $7.8(3.9)$ & $6.8(3.4)$ & $.012^{\mathrm{b}}$ & $61.9(32.2)$ & $57.2(28.2)$ & $.028^{\mathrm{b}}$ \\
\hline $\mathrm{C} 7 / \mathrm{Tl}$ & $8.8(4.9)$ & $6(3.5)$ & $<.001^{\mathrm{b}}$ & $71.1(40.5)$ & $56.7(32.5)$ & $<.001^{\mathrm{b}}$ \\
\hline
\end{tabular}

${ }^{a}$ Analysis of covariance adjusted for age and BMI, smoking history, heart disease, and hypertension was used. In the ANCOVA for frequency of vessels, ranked variables were used.

${ }^{\mathrm{b}}$ An $\alpha$ level of .05 was considered significant.

secondary vessels was also significantly higher at all 4 levels in patients with MS $(P<.03)$. The difference was most significant at the $\mathrm{C} 7 / \mathrm{T} 1$ level where the CSA of patients with MS was $71.1 \pm$ $40.5 \mathrm{~mm}^{2}$ compared with $56.7 \pm 32.5 \mathrm{~mm}^{2}$ in $\mathrm{HC}(P<.001)$. No significant differences in the CSA of the IJVs were found between MS and HC cohorts. Figure 2 shows an example of the differences in vessel number and CSA observed in patients with MS and ageand sex-matched HC.

In a subgroup of subjects without cardiovascular risk factors, the comparison between patients with MS $(n=135)$ and $\mathrm{HC}(n=$ 142 ) yielded results like those in the main analyses for arterial, venous, and secondary vessel frequency and their CSAs (On-line Tables 3 and 4). Except for the number of secondary vessels on the C5/C6 level (7.0 versus 8.3, $P=.034$ ), MS smokers showed no significant differences compared with MS nonsmokers (Online Tables 5 and 6).

\section{DISCUSSION}

Two main findings were identified in this study. First, even after adjusting for all cardiovascular factors including BMI, hypertension, heart disease, smoking history, and age, the MS cohort showed a higher frequency of secondary neck vessels and larger CSAs compared with HC. This finding was consistent through all cervical levels examined. Most interesting, the patients with MS also had a smaller arterial CSA of the main and secondary arterial vessels (CCA, ICA, ECA, and VA, respectively). Furthermore, these findings were reconfirmed in a subgroup of subjects (70\%) without the presence of cardiovascular comorbidities. In addition, we showed that demographic factors, such as age and BMI, are essential confounders between patients with MS and $\mathrm{HC}$ when considering the morphology of neck vessels and should be controlled for in future studies.

The finding that patients with MS show different patterns of vascular neck vessel morphology with respect to aging compared with $\mathrm{HC}$ would suggest that MS and cardiovascular disease have intertwining pathways. ${ }^{10}$ Cardiovascular risk factors are known to contribute to MS disease severity. For example, smoking has been associated with higher lesion burden and more severe brain atrophy in patients with MS. ${ }^{7}$ When several cardiovascular comorbidities are combined, this relationship becomes even more robust. ${ }^{6}$ Two independent epidemiologic studies showed an interesting disparity of decreased prevalence of ischemic heart disease and an increased prevalence of stroke in patients with MS compared with HC. ${ }^{21,22}$ This finding would suggest that the arterial vessels supplying the central nervous system are possibly subject to particular atherosclerotic harm. ${ }^{23}$ In fact, 1 study showed that patients with MS had decreased carotid compliance compared with HC. ${ }^{23}$ Although the decreased arterial lumen of the carotid and vertebral arteries found in MS patients may suggest that inflammatory mechanisms contribute to early atherosclerosis in MS patients, ${ }^{24}$ we found similar results in the subgroup of MS patients without presence of cardiovascular diseases. Other authors have also shown lower CCA values in patients with MS compared with HC (65 versus $\left.78 \mathrm{~mm}^{2}\right){ }^{25}$ Another MS study that used a phase-contrast MRV technique showed a somewhat higher CSA CCA area compared with our measurements using time-of-flight MRV (65 versus $48.9 \mathrm{~mm}^{2}$, respectively). ${ }^{26}$ Heterogeneity of the population of patients with MS between the 2 studies can also contribute to explanation of these findings. Therefore, future studies should investigate this issue in more detail at disease onset, when the presence of cardiovascular risks is minimal.

The hypoperfusion of the normal-appearing white matter commonly detected in patients with MS may be partially linked to the anatomic differences of the neck arterial system observed in the present study. ${ }^{27}$ Decreased cerebral blood flow in both the normal-appearing white matter and the gray matter has been previously reported. ${ }^{11}$ Distinct perfusion clusters in patients with MS 


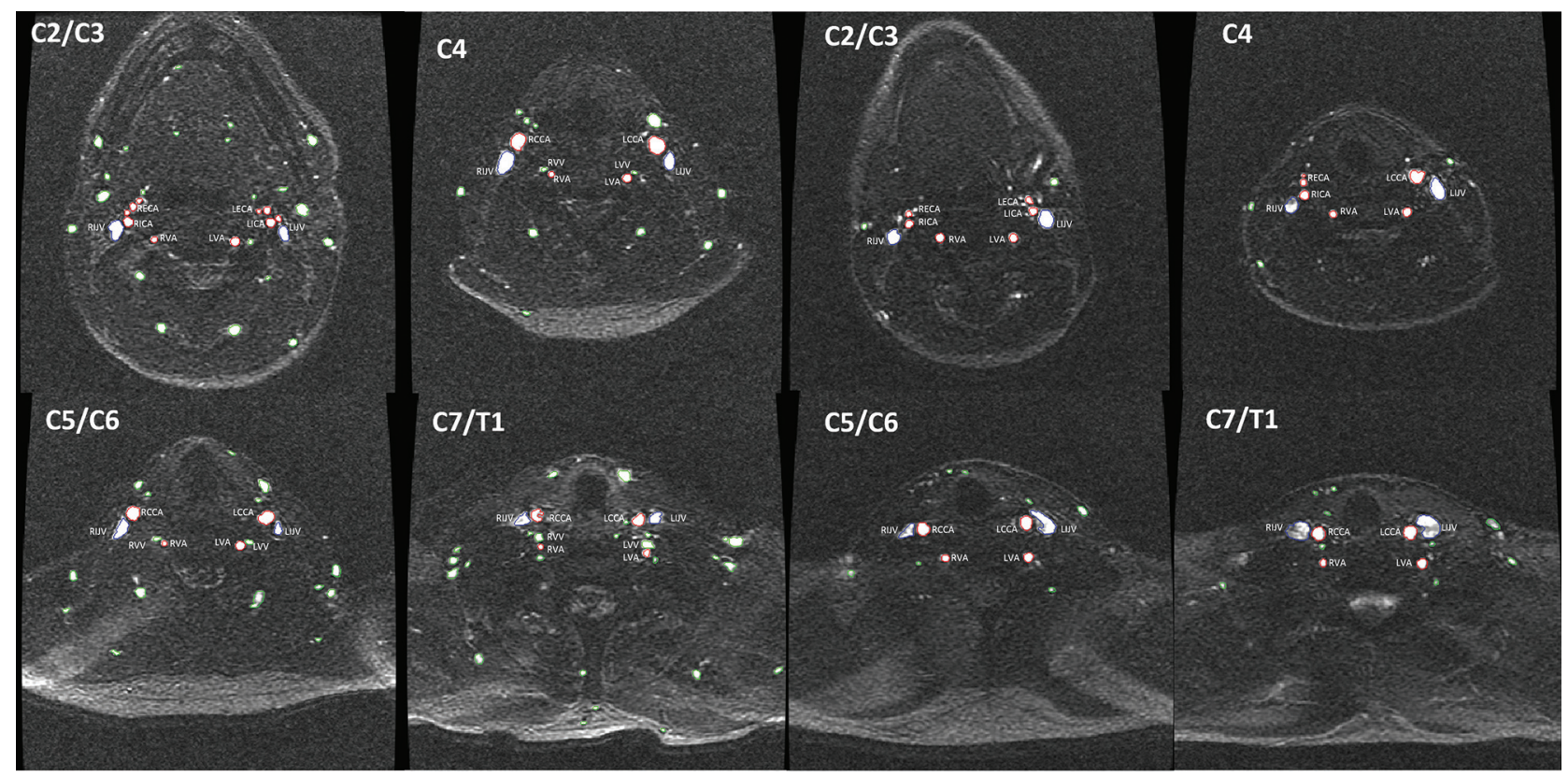

FIG 2. Comparison of main and secondary vessel number and cross-sectional area on a 2D-MRV sequence at 4 cervical levels in patients with multiple sclerosis (4 corresponding panels on the left) and age- and sex-matched healthy controls (4 corresponding panels on the right). VV indicates vertebral vein; L, left; $R$, right. Green color represents the secondary vessels, red color represents the CCA, ICA, EAC, and VA, while blue represents the IJV.

showed associations of local hypoperfusion and formation of T1hypointense lesions, highlighting the need for better perfusion in lesion repair. ${ }^{28}$ Most important, the hypoperfusion observed in the GM, in an absence of volume loss, indicates that decreased brain perfusion might be a temporal predecessor to brain atrophy development in MS. ${ }^{29}$ Even though there is growing evidence of coexisting vascular pathology in MS, the current perfusion studies are generally of small sample size and limited effect size. Therefore, caution in any interpretation of direct causality is warranted.

Neurovascular coupling is a physiologic mechanism responsible for increasing the cortical blood flow due to cell activation. ${ }^{30}$ In healthy individuals, this results in cerebral vasodilation that is compensating for the increased demand of glucose and oxygen. ${ }^{31}$ A hypocapnic study showed that patients with MS are unable to physiologically increase cerebral blood flow, which, in turn, leads to global diffuse hypoperfusion. ${ }^{13}$ This abnormality has been previously linked as a triggering factor for MS lesion formation and may explain, to some extent, the neurodegenerative aspect of the MS disease process. ${ }^{32}$ Overall, the morphologic changes to the neck arteries supplying the brain that were observed in this study may be a consequence of prolonged normal-appearing white matter/GM hypoperfusion and impaired cerebrovascular reactivity, which leads to accelerated neurodegeneration in MS.

An alternative inverse explanation for the decrease of arterial CSA observed in this study could be related to the increase of disability, which causes less physical activity in patients with MS. ${ }^{4}$ Because worsening disability causes a sedentary lifestyle, this will eventually lead to an increase of the cardiovascular burden and vascular complications. ${ }^{4}$ Additionally, measures to improve the reserve-related activities and maintaining strenuous activities have resulted in better clinical and MR imaging-derived MS outcomes. While the present study cannot answer whether the morphologic changes of the neck arteries observed are secondary or primary to the MS disease process, future studies should extend our preliminary findings in early and more advanced MS disease stages using a longitudinal study design.

When the size of IJVs between the MS and HC cohorts was compared, no differences were found between the 2 groups at any cervical level. Therefore, our findings are in line with several recent MRV studies showing no IJV anatomic differences between patients with MS and $\mathrm{HC},{ }^{33,34}$ but contrary to some other studies showing the opposite findings. ${ }^{26,35,36}$ Several recent studies demonstrated that the IJV CSA has marked variability in its course through the neck and increased narrowing with aging. ${ }^{20,37}$

Several studies used MRV to examine the prevalence and the extent of secondary vessels in the necks of patients with MS. One study showed an increased frequency of posterior paraspinal collaterals in patients with MS. ${ }^{36}$ In another study, there was a trend toward greater occurrence of non-IJV collaterals. ${ }^{35}$ Yet another study reported no differences between patients with MS and HC in the secondary neck vessels using $5 \mathrm{~mm}^{2}$ as their cutoff for identification. ${ }^{33}$ On the contrary, using $2 \mathrm{~mm}^{2}$ as a cutoff in the present study, we showed that patients with MS had a significantly increased frequency of secondary neck vessels and their CSAs. In the present study, no phase-contrast imaging was used, which did not allow us to characterize the secondary neck vessels with respect to their arterial or venous components; therefore, the increased frequency of secondary neck vessels may represent arterial or venous collateralization. On the other hand, a large phasecontrast MRV study showed that patients with MS had lower IJV and higher paraspinal venous flow, compared with HC. ${ }^{38}$ While our study cannot answer this question, one of the possible hypotheses could be that the decreased size of the carotid and vertebral arterial supply to the CNS could result in secondary arterial compensation mechanisms.

Age is an important factor in the development of venous he- 
modynamic changes in the neck. In this study, increased age showed an association with fewer secondary vessels in the neck of HC. In addition, an increase in the BMI showed an association with a decreased frequency of neck vessels measured at all levels in both MS and HC groups. The effects of age and BMI on morphologic changes of the IJVs in a healthy aging population have been previously described. ${ }^{20,39}$ Even when we corrected for the previously aforementioned risk factors, the MS cohort displayed an increased secondary neck vessel frequency and secondary vessel CSA, compared with HC. The differences were the most robust both at the $\mathrm{C} 2 / \mathrm{C} 3$ level, representing vessels at the base of the skull, and at C7/T1 level, representing the level of the superior thoracic outlet. Therefore, while in $\mathrm{HC}$ we found a decrease of the number of secondary vessels with aging, this association was lacking in patients with MS; this finding suggests a possible disease effect on vascular recruitment.

The additional vascularization may be triggered by either the recurrent hypoperfusion of the brain or inflammatory factors involved in the complex remodeling of preexisting conduits running alongside the main arteries. ${ }^{40,41}$ For example, the T helper 17 cell subset and interleukin 17 have been linked as essential in both the severity of MS and as an important factor in neovascularization. ${ }^{41}$

Dynamic flow quantification of the secondary vasculature could further aid in understanding the anatomic flow differences of secondary neck vessels observed in this study, providing flow data rather than purely structural measurements. Furthermore, the current time-of-flight MRV technique allows segmentation of only the luminal aspect of the vessel and not of the anatomic CSA. Any regions of bidirectional flow, absence of flow, and flow nonhomogeneity may create partially inaccurate vessel-size estimation. Regarding the hemodynamic properties, measuring the luminal CSA might be a better anatomic proxy than inclusion of the thickness of the vessel wall. Additionally, studies associating the morphology of the neck vasculature with dynamic brain perfusion will provide an important answer to the anatomic and dynamic vascular role of these vessels in the complex pathogenesis of MS. The major strength of the study is the use of a large 1:1 matched sample of HC and patients with MS, which decreased the potential comparison bias between the 2 study populations. An additional longitudinal study, using phase contrast and examining the atherosclerotic burden, should further address the limitations of the current study design. Because this was an observational study, we did not adjust for multiple comparisons in our statistical analyses. Therefore, larger longitudinal studies should confirm our preliminary findings.

\section{CONCLUSIONS}

Patients with MS showed lower CSAs of the carotid and vertebral arteries and a higher frequency of secondary neck vessels and their CSAs compared with HC. These findings may suggest that the inflammatory mechanisms, which are present in patients with MS from early onset, may contribute to accelerated atherosclerosis in patients with MS. The higher frequency of secondary neck vessels may suggest that the decreased size of the carotid and vertebral arterial supply to the CNS could lead to the formation of secondary arterial compensation mechanisms. However, further replica- tion and continuation of the research are warranted before final conclusions can be drawn.

Disclosures: Christopher Magnano-UNRELATED: Employment: General Electric, Comments: independent of the work presented in this article. Bianca WeinstockGuttman-UNRELATED: Consultancy: Biogen Idec, Teva Neuroscience, EMD Serono, Novartis, Genzyme \& Sanofi, Genetech*; Grants/Grants Pending: Biogen Idec, Teva Neuroscience, EMD Serono, Novartis, Genzyme \& Sanofi*; Payment for Lectures Including Service on Speakers Bureaus: Biogen Idec, Teva Neuroscience, EMD Serono, Novartis, Genzyme \& Sanofi, Genentech. Robert Zivadinov-UNRELATED: Consultancy: Genzyme-Sanofi, Novartis; Grants/Grants Pending: Genzyme-Sanofi, Intekrin-Coherus, Novartis, IMS Health*; Payment for Lectures Including Service on Speakers Bureaus: Genzyme-Sanofi, Novartis*. *Money paid to the institution.

\section{REFERENCES}

1. Lucchinetti CF, Bruck W, Lassmann H. Evidence for pathogenic heterogeneity in multiple sclerosis. Ann Neurol 2004;56:308 CrossRef Medline

2. Xia Z, White CC, Owen EK, et al. Genes and Environment in Multiple Sclerosis project: a platform to investigate multiple sclerosis risk. Ann Neurol 2016;79:178-89 CrossRef Medline

3. Marrie RA, Reider N, Cohen J, et al. A systematic review of the incidence and prevalence of cardiac, cerebrovascular, and peripheral vascular disease in multiple sclerosis. Mult Scler 2015;21:318-31 CrossRef Medline

4. Klaren RE, Hubbard EA, Wetter NC, et al. Objectively measured sedentary behavior and brain volumetric measurements in multiple sclerosis. Neurodegener Dis Manag 2017;7:31-37 CrossRef Medline

5. Dagan A, Gringouz I, Kliers I, et al. Disability progression in multiple sclerosis is affected by the emergence of comorbid arterial hypertension. J Clin Neurol 2016;12:345-50 CrossRef Medline

6. Kappus N, Weinstock-Guttman B, Hagemeier J, et al. Cardiovascular risk factors are associated with increased lesion burden and brain atrophy in multiple sclerosis. J Neurol Neurosurg Psychiatry 2016;87: 181-87 CrossRef Medline

7. Zivadinov R, Weinstock-Guttman B, Hashmi K, et al. Smoking is associated with increased lesion volumes and brain atrophy in multiple sclerosis. Neurology 2009;73:504-10 CrossRef Medline

8. Weinstock-Guttman B, Zivadinov R, Mahfooz N, et al. Serum lipid profiles are associated with disability and MRI outcomes in multiple sclerosis. J Neuroinflammation 2011;8:127 CrossRef Medline

9. Kavak KS, Teter BE, Hagemeier J, et al; New York State Multiple Sclerosis Consortium. Higher weight in adolescence and young adulthood is associated with an earlier age at multiple sclerosis onset. Mult Scler 2015;21:858-65 CrossRef Medline

10. Thormann A, Magyari M, Koch-Henriksen N, et al. Vascular comorbidities in multiple sclerosis: a nationwide study from Denmark. J Neurol 2016;263:2484-93 CrossRef Medline

11. D'Haeseleer M, Hostenbach S, Peeters I, et al. Cerebral hypoperfusion: a new pathophysiologic concept in multiple sclerosis? J Cereb Blood Flow Metab 2015;35:1406-10 CrossRef Medline

12. Sun X, Tanaka M, Kondo S, et al. Clinical significance of reduced cerebral metabolism in multiple sclerosis: a combined PET and MRI study. Ann Nucl Med 1998;12:89-94 CrossRef Medline

13. Marshall O, Lu H, Brisset JC, et al. Impaired cerebrovascular reactivity in multiple sclerosis. JAMA Neurol 2014;71:1275-81 CrossRef Medline

14. Marshall O, Chawla S, Lu H, et al. Cerebral blood flow modulation insufficiency in brain networks in multiple sclerosis: a hypercapnia MRI study. J Cereb Blood Flow Metab 2016;36:2087-95 CrossRef Medline

15. Sadeghian M, Mastrolia V, Rezaei Haddad A, et al. Mitochondrial dysfunction is an important cause of neurological deficits in an inflammatory model of multiple sclerosis. Sci Rep 2016;6:33249 CrossRef Medline

16. Zivadinov R, Ramasamy DP, Benedict RR, et al. Cerebral microbleeds in multiple sclerosis evaluated on susceptibility-weighted im- 
ages and quantitative susceptibility maps: a case-control study. $R a-$ diology 2016;281:884-95 CrossRef Medline

17. Polman CH, Reingold SC, Banwell B, et al. Diagnostic criteria for multiple sclerosis: 2010 revisions to the McDonald criteria. Ann Neurol 2011;69:292-302 CrossRef Medline

18. Chobanian AV, Bakris GL, Black HR, et al; Joint National Committee on Prevention, Detection, Evaluation, and Treatment of High Blood Pressure. National Heart, Lung, and Blood Institute, National High Blood Pressure Education Program Coordinating Committee. Seventh Report of the Joint National Committee on Prevention, Detection, Evaluation, and Treatment of High Blood Pressure. Hypertension 2003;42:1206-52 CrossRef Medline

19. Gisolf J, van Lieshout JJ, van Heusden K, et al. Human cerebral venous outflow pathway depends on posture and central venous pressure. J Physiol 2004;560:317-27 CrossRef Medline

20. Magnano, Belov, Krawiecki J, et al. Internal jugular vein cross-sectional area enlargement is associated with aging in healthy individuals. PLoS One 2016;11:e0149532 CrossRef Medline

21. Allen NB, Lichtman JH, Cohen HW, et al. Vascular disease among hospitalized multiple sclerosis patients. Neuroepidemiology 2008;30: 234-38 CrossRef Medline

22. Christiansen CF. Risk of vascular disease in patients with multiple sclerosis: a review. Neurol Res 2012;34:746-53 CrossRef Medline

23. Ranadive SM, Yan H, Weikert M, et al. Vascular dysfunction and physical activity in multiple sclerosis. Med Sci Sports Exerc 2012;44: 238-43 CrossRef Medline

24. Minagar A, Jy W, Jimenez JJ, et al. Multiple sclerosis as a vascular disease. Neurol Res 2006;28:230-35 CrossRef Medline

25. Feng W, Utriainen D, Trifan G, et al. Quantitative flow measurements in the internal jugular veins of multiple sclerosis patients using magnetic resonance imaging. Rev Recent Clin Trials 2012;7: 117-26 CrossRef Medline

26. Haacke EM, Feng W, Utriainen D, et al. Patients with multiple sclerosis with structural venous abnormalities on MR imaging exhibit an abnormal flow distribution of the internal jugular veins. $J$ Vasc Interv Radiol 2012;23:60-68.e1-3 CrossRef Medline

27. ElSankari S, Balédent $\mathrm{O}$, van Pesch V, et al. Concomitant analysis of arterial, venous, and CSF flows using phase-contrast MRI: a quantitative comparison between MS patients and healthy controls. J Cereb Blood Flow Metab 2013;33:1314-21 CrossRef Medline

28. Narayana PA, Zhou Y, Hasan KM, et al. Hypoperfusion and T1hypointense lesions in white matter in multiple sclerosis. Mult Scler 2014;20:365-73 CrossRef Medline

29. Debernard L, Melzer TR, Van Stockum S, et al. Reduced grey matter perfusion without volume loss in early relapsing-remitting multiple sclerosis. J Neurol Neurosurg Psychiatry 2014;85:544-51 CrossRef Medline

30. Salinet AS, Robinson TG, Panerai RB. Effects of cerebral ischemia on human neurovascular coupling, $\mathrm{CO} 2$ reactivity, and dynamic cerebral autoregulation. J Appl Physiol (1985) 2015;118:170-77 CrossRef Medline

31. $\mathrm{Lu} \mathrm{H}, \mathrm{Xu} \mathrm{F}$, Rodrigue KM, et al. Alterations in cerebral metabolic rate and blood supply across the adult lifespan. Cereb Cortex 2011; 21:1426-34 CrossRef Medline

32. Prinster A, Quarantelli M, Orefice G, et al. Grey matter loss in relapsing-remitting multiple sclerosis: a voxel-based morphometry study. Neuroimage 2006;29:859-67 CrossRef Medline

33. Zivadinov R, Lopez-Soriano A, Weinstock-Guttman B, et al. Use of MR venography for characterization of the extracranial venous system in patients with multiple sclerosis and healthy control subjects. Radiology 2011;258:562-70 CrossRef Medline

34. Wattjes MP, van Oosten BW, de Graaf WL, et al. No association of abnormal cranial venous drainage with multiple sclerosis: a magnetic resonance venography and flow-quantification study. J Neurol Neurosurg Psychiatry 2011;82:429-35 CrossRef Medline

35. McTaggart RA, Fischbein NJ, Elkins CJ, et al. Extracranial venous drainage patterns in patients with multiple sclerosis and healthy controls. AJNR Am J Neuroradiol 2012;33:1615-20 CrossRef Medline

36. Zaharchuk G, Fischbein NJ, Rosenberg J, et al. Comparison of MR and contrast venography of the cervical venous system in multiple sclerosis. AJNR Am J Neuroradiol 2011;32:1482-89 CrossRef Medline

37. Buch K, Groller R, Nadgir RN, et al. Variability in the cross-sectional area and narrowing of the internal jugular vein in patients without multiple sclerosis. AJR Am J Roentgenol 2016;206:1082-86 Medline

38. Sethi SK, Daugherty AM, Gadda G, et al. Jugular anomalies in multiple sclerosis are associated with increased collateral venous flow. AJNR Am J Neuroradiol 2017;38:1617-22 CrossRef Medline

39. Magnano $C$, Belov $P$, Krawiecki J, et al. Internal jugular vein narrowing and body mass index in healthy individuals and multiple sclerosis patients. Veins and Lymphatics 2014;3:4632 CrossRef

40. Koerselman J, van der Graaf Y, de Jaegere PP, et al. Coronary collaterals: an important and underexposed aspect of coronary artery disease. Circulation 2003;107:2507-11 Medline

41. la Sala A, Pontecorvo L, Agresta A, et al. Regulation of collateral blood vessel development by the innate and adaptive immune system. Trends Mol Med 2012;18:494-501 CrossRef Medline 